\title{
REPEAT CATHETERIZATION IN VENTRICULAR SEPTAL DEFECT AND PULMONARY HYPERTENSION
}

\author{
BY \\ G. HOWITT AND E. G. WADE \\ From University Department of Cardiology, Manchester Royal Infirmary \\ Received February 15, 1962
}

Although it has been shown that children with a large ventricular septal defect frequently develop heart failure during infancy (Marquis, 1950; Morgan, Griffiths, and Blumenthal, 1960) it is our experience that if they can be tided over this period they often improve spontaneously and remain well for many years.

The tendency to maintain this improvement is unexpected: deterioration appears more likely owing to progressive pulmonary vascular disease resulting from prolonged exposure of the pulmonary arterial system to systemic pressures. Hæmodynamic data are scanty and mainly derived from single catheter studies: the classic paper is that of Brotmacher and Campbell (1958) who concluded that the pulmonary vascular resistance tended to rise with advancing years, a contention supported by Goodwin (1960). Few serial catheterization studies have been reported, particularly in patients with pulmonary hypertension(Kay, Zimmerman, and Cross, 1955; Adams et al., 1959; Fyler et al., 1958; Downing, 1959) but recently Lynfield et al. (1961) gave data from serial studies on a large number of patients, several of whom did have severe pulmonary hypertension. In these hypertensive patients they found no tendency to progressive elevation of the pulmonary vascular resistance.

This aspect of the natural history is of theoretical and practical importance. We therefore re-catheterized 10 children who, on initial investigation three to seven years previously, were found to have a large ventricular septal defect, a left-to-right shunt, and systemic pressures in the right ventricle. In this paper we report our results.

\section{SubJECTS AND MeTHOdS}

The 10 patients, 4 girls and 6 boys, first attended the Department of Cardiology, Manchester Royal Infirmary, at ages ranging from 2 years 11 months to 15 years. All were subjected to routine clinical, radiological, and electrocardiographic examination and underwent cardiac catheterization. They all had a large ventricular septal defect, a left-to-right shunt, and systemic pressures in the right ventricle. In 8, the pulmonary resistance was elevated (over 200 c.g.s. units) and the pulmonary systolic pressure was over $65 \mathrm{~mm}$. Hg; they, therefore, corresponded to Group 4 of Brotmacher and Campbell and Group III of Lynfield et al. The other 2 children had infundibular pulmonary stenosis at the time of the first catheterization. After intervals of between three and seven years they were completely re-examined and re-catheterized. The height and weight on each occasion were plotted on Wetzel's guide for evaluating physical fitness in terms of physique; the physique channels range through A4 (obese); A3, A2 (stocky); A, M, B1 (good); B2 (fair); B3 (borderline); B4 (poor).

Cardiac catheterization was carried out in the usual manner, premedication being with heroin or a mixture of chlorpromazine, pethidine, and phenergan in the younger, and seconal in the older children.

In all patients below the age of 12 years, oxygen consumption was calculated by the method used by Lynfield et al. (1961) based on the basal metabolic rate at different ages; in the remainder it was calculated on the assumption of a normal oxygen consumption of $140 \mathrm{ml} . / \mathrm{min} . / \mathrm{m} .^{2}$ of body surface. 
Pulmonary and systemic blood flows were calculated from standard formulæ, and to permit comparison at different ages, flows and resistances have been expressed in relation to body surface area, that is as "indices." Pulmonary artery "wedge" pressures were not obtained in all instances, and in this paper when pulmonary resistance is referred to it is total pulmonary resistance. The systemic arterial oxygen saturation was not estimated at the time of the first investigation in 6 children; all were fully saturated at the second investigation and were assumed to be the same at the time of the first, for the purpose of calculating shunts.

Systemic pressure measurements were by the cuff method in all cases.

\section{RESULTS}

The clinical, electrocardiographic, and radiological data from the 10 patients are given in Table I. No X-ray films are available corresponding to the time of the first catheterization in Cases 7 and 9. Only standard limb lead electrocardiograms were taken at the time of the first investigation in Case 7.

TABLE I

Clinical, Electrocardiographic, and Radiological data at the Time of the First and Second Catheterization

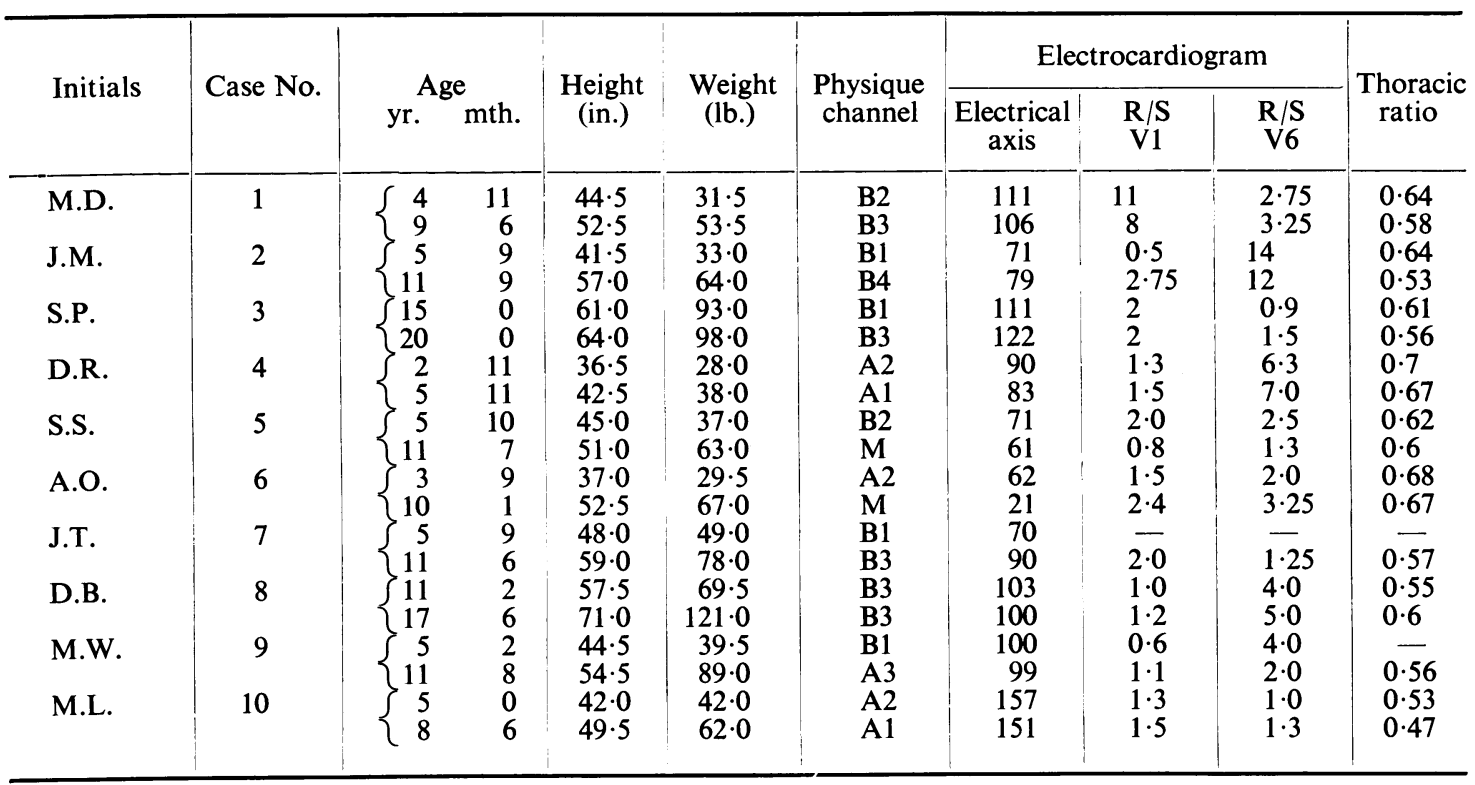

The hæmodynamic data are given in Table II. Two patients had some degree of infundibular stenosis when first investigated and of the remaining 8 who did not, 2 had developed it when investigated for the second time. Thus the children divide into three groups.

\section{(1) Those Without Infundibular Pulmonary Stenosis}

There were 6 patients, Cases 3 to 8 (Tables I and II). There was no significant change in the symtomatology or in the physical signs in any child in this group over the period of observation. One was in a better physique channel at the time of the second investigation, another remained in the same, the other 4 were all in a lower channel when examined the second time.

The cardiothoracic ratio became slightly less in 4 and slightly greater in 1 patient. The electrical axis remained virtually the same in 2 , moved to the right in 2 , and to the left in 2 patients. There was no noteworthy change in ventricular preponderance as reflected in the $\mathrm{R} / \mathrm{S}$ ratio in leads $\mathrm{V} 1$ and V6.

In 3 children (Cases 3, 5, and 8 ) the mean pulmonary artery pressure remained unaltered. In 2 (Cases 4 and 7) there were falls in the mean pressure of 17 and $16 \mathrm{~mm}$. $\mathrm{Hg}$ respectively to levels

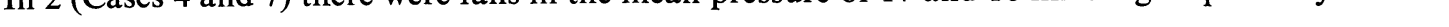


TABLE II

Hemodynamic Data at Time of First and Second Catheterization

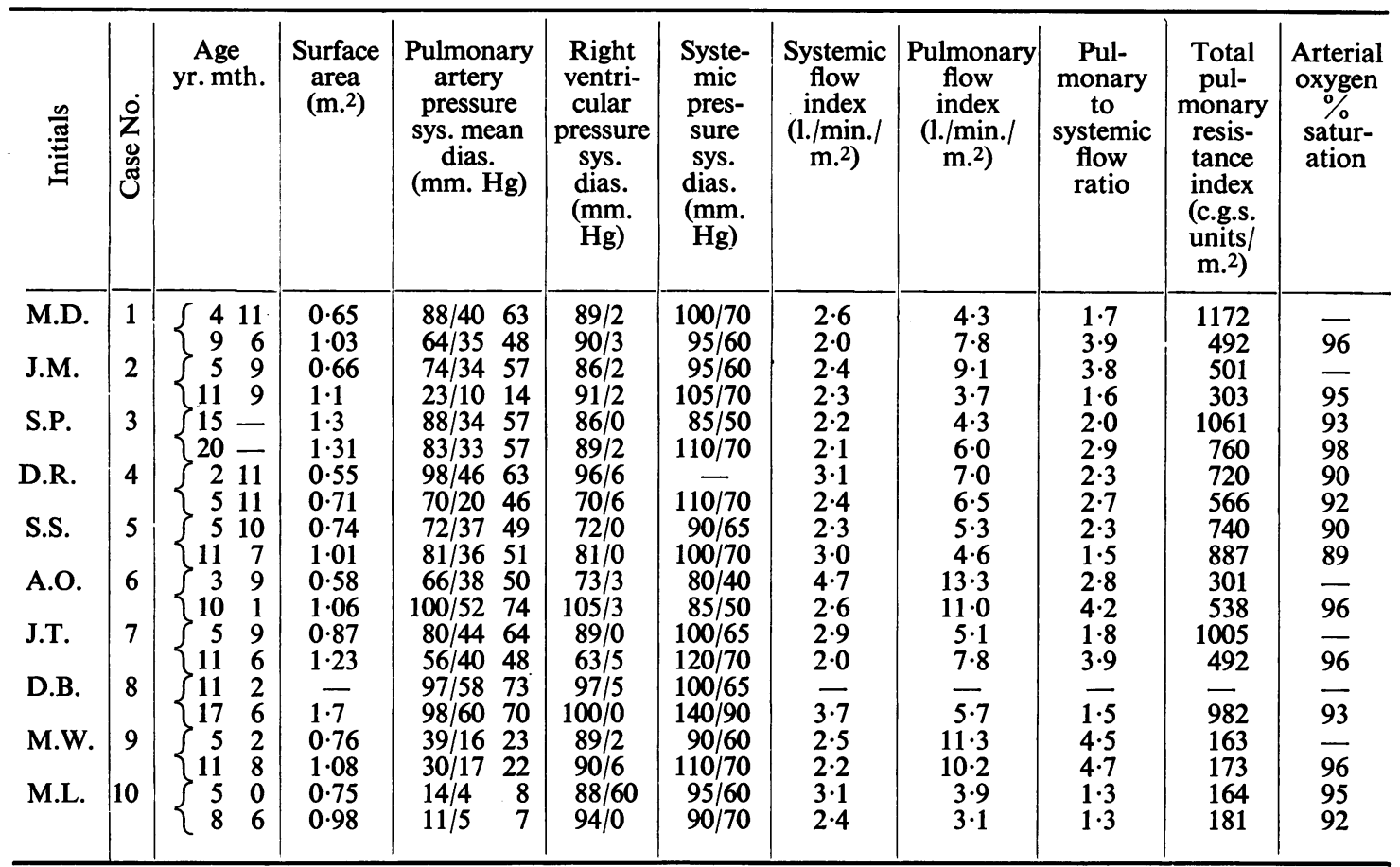

appreciably below systemic pressures. In the remaining child (Case 6) the pressure rose $24 \mathrm{~mm}$. $\mathrm{Hg}$. These changes are shown as continuous lines in Fig. 1. The drop in pressure in Cases 4 and 7 was associated with falls in pulmonary resistance index from 720 to 566 and 1005 to 492 units respectively. In Case 7 the pulmonary flow index rose nearly 50 per cent but was unchanged in Case 4 . In those with constant pressures one (Case 3 ) showed a fall in pulmonary resistance index from 1061 to 760 units and a rise in pulmonary flow index from $4 \cdot 3$ to $6.01 . / \mathrm{min}$. In Case 8 flows were unfortunately not calculated at the first catheterization. In Case 6 the pulmonary hypertension was mainly hyperkinetic and the rise was associated with a slight fall in flow and an increase in pulmonary resistance index from 301 to 538 units.

Systemic blood flow increased in 1 child (Case 5), was unchanged in 4, and not estimated on the first occasion in Case 8. Case 3 was 15 years old when first catheterized and did not grow in the years separating the two investigations; the systemic flow index was unaltered. In the other 3 children systemic flow index fell as growth proceeded. The behaviour of these various parameters is shown as continuous lines in Fig. 2-5.

\section{(2) Those Developing Infundibular Pulmonary Stenosis}

There were 2 who developed stenosis (Cases 1 and 2, Tables I and II and M.D. and J.M. in Fig.1-5). Case 1 developed mild pulmonary stenosis between the age of 4 years 11 months and 9 years 6 months. There was no change in her symptoms nor in the physical signs over the period of observation. The cardiothoracic ratio became slightly less, and the electrocardiogram showed, if anything, evidence of less right and more left ventricular preponderance. A systolic gradient across the right ventricular outflow tract of $26 \mathrm{~mm}$. $\mathrm{Hg}$ developed, the pulmonary arterial pressure fell from $88 / 40$, mean 63 , to $64 / 35$, mean $48 \mathrm{~mm}$. Hg. The right ventricular pressure remained at systemic levels and the shunt left to right. The pulmonary flow index rose from 4.3 to $7 \cdot 81 . / \mathrm{min}$., and the 
Fig. 1 to 5.-Diagrams to show the changes in hæmodynamics over the period of observation.

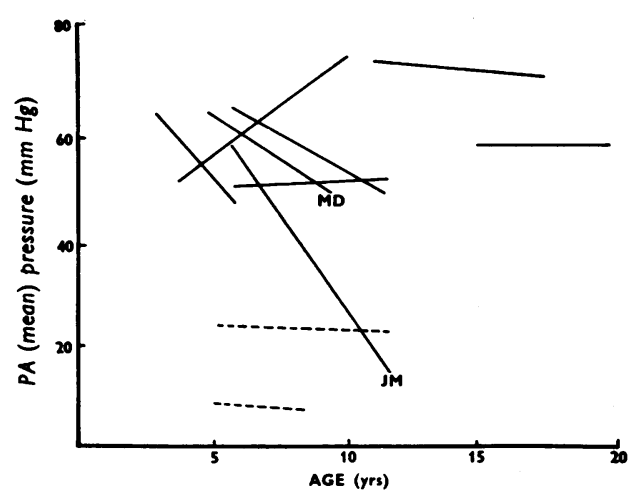

Fig. 1.-Pulmonary arterial (mean) pressure.

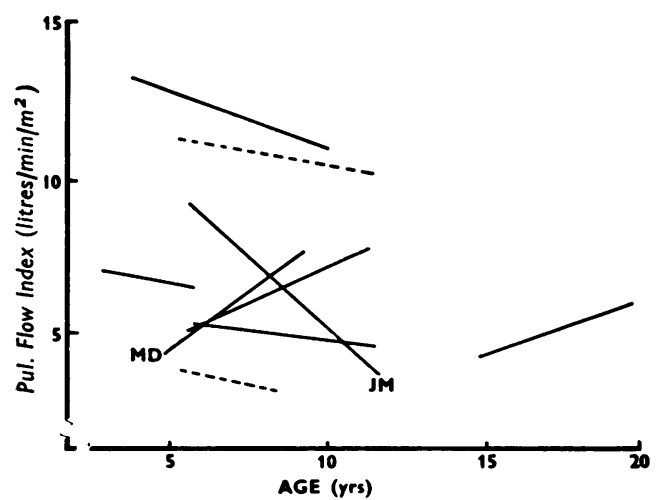

Fig. 2.-Pulmonary flow index.

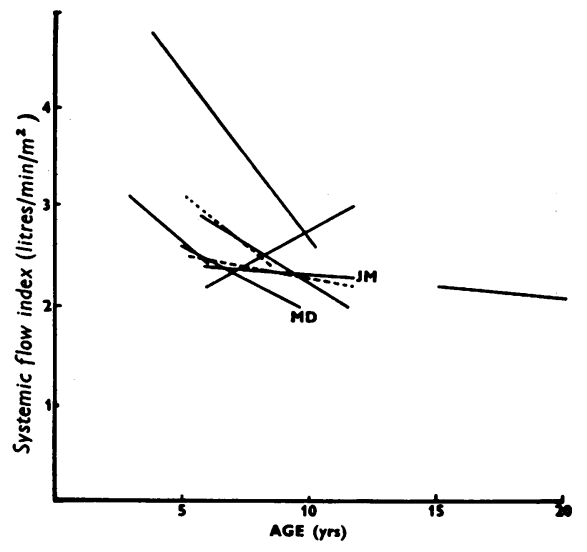

Fig. 3.-Systemic flow index.

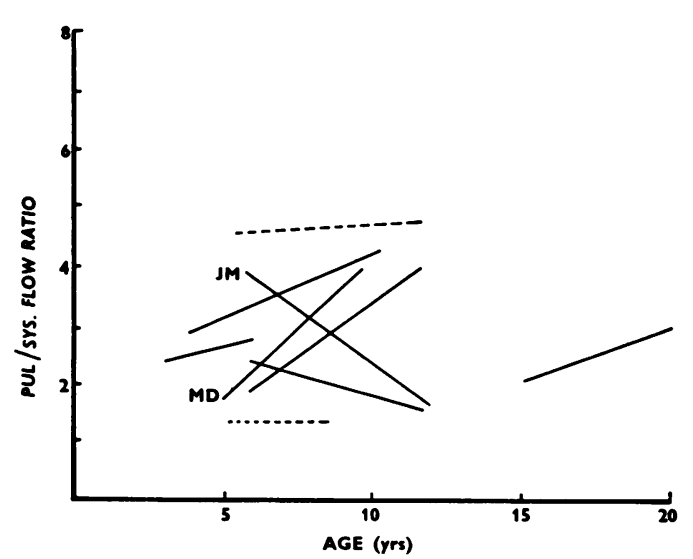

FIG. 4.-Pulmonary/systemic flow ratio.

pulmonary to systemic flow ratio rose from 1.7 to 3.9 . The pulmonary resistance index fell from 1172 to 492 c.g.s. units. The systemic flow index fell from 2.6 to 2.01 ./min.

Case 2 developed more severe pulmonary stenosis between the age of 5 years 9 months and 11 years 9 months. There was no change in his symptoms and he developed normally, rising to a higher physique channel. At the time of the first catheterization there was a very loud pulmonary second sound, a pulmonary diastolic murmur, and a mitral flow murmur. When investigated again, the pul-

Fig. 5.-Pulmonary resistance index. 
monary second sound was softer and there was no pulmonary or apical diastolic murmur. The cardiothoracic ratio diminished considerably and the pulmonary artery shadows were less prominent (Fig. 6A and B). The electrocardiogram also changed (Fig. 7): there was more evidence of right and less of left ventricular enlargement as shown by the R/S ratios in V1 and V6, the Q waves in V5 and V6 became smaller, and the $T$ waves upright.

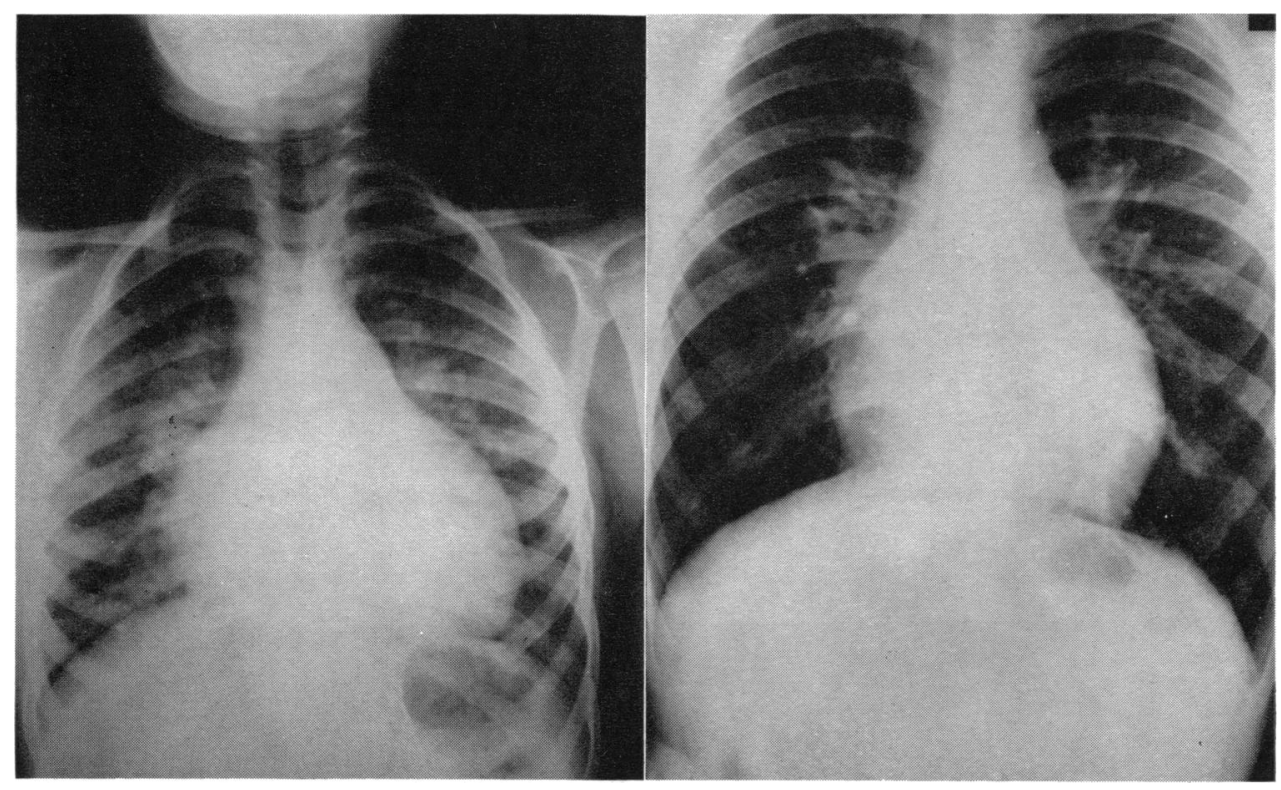

A

B

Fig. 6. - Case 2 (J.M.). Development of infundibular pulmonary stenosis. Chest radiograph (A) age 5 yr. 9 mth., (B) age 11 yr. 9 mth.

There was a systolic gradient of 12 at the first catheterization, and this increased to $68 \mathrm{~mm}$. $\mathrm{Hg}$. The pulmonary artery pressure fell from $74 / 34$ mean 57 to $23 / 10$ mean $14 \mathrm{~mm}$. $\mathrm{Hg}$, the right ventricular pressure remaining systemic and the shunt left to right. The pulmonary flow index was cut from $9 \cdot 1$ to $3 \cdot 71$. $/ \mathrm{min}$. and the pulmonary to systemic flow ratio from 3.8 to $1 \cdot 6$. The pulmonary resistance index fell from 501 to 303 units. The systemic flow index was unchanged. The behaviour of these various parameters is shown in Fig. 1-5 (M.D. and J.M.).

\section{(3) Those with Infundibular Pulmonary Stenosis}

Cases 9 and 10 developed no change clinically and they progressed well physically. One child showed evidence of more right ventricular enlargement on the electrocardiogram. When first investigated at the age of 5 years they had systolic gradients of 50 and $74 \mathrm{~mm}$. Hg. After intervals of five and three years there was remarkably little change in the dynamics. The pressure gradient was unaltered and both pulmonary flow index and pulmonary to systolic flow ratios and pulmonary resistance index were almost identical.

In both the systemic flow index fell slightly. These data are shown as dotted lines in Fig. 1-5. 


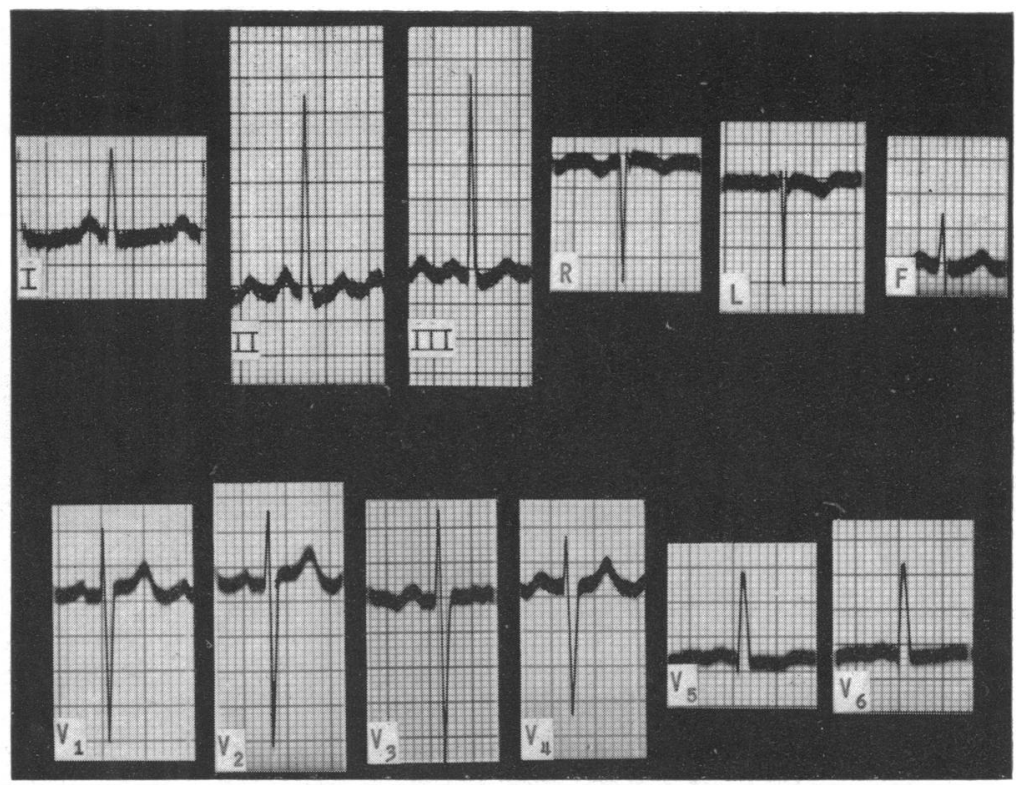

A

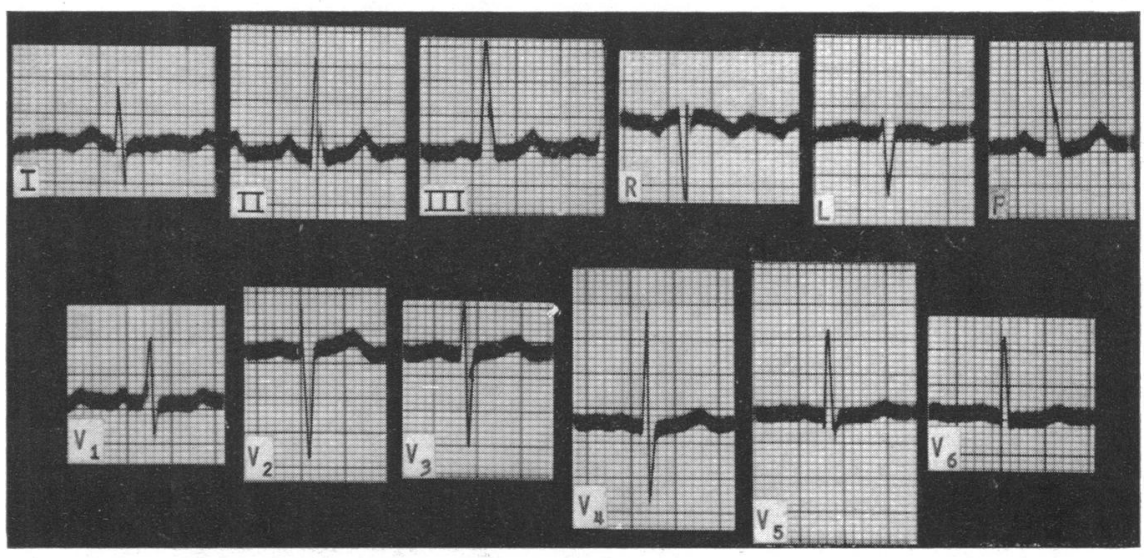

B

Fig. 7.-Case 2 (J.M.). Development of infundibular pulmonary stenosis. Electrocardiogram (A) age 5 yr. 9 mth., (B) age 11 yr. 9 mth.

\section{Discussion}

When intracardiac communications are present, the exact estimation of pulmonary and systemic flows and therefore resistances is open to considerable error and only large differences can be con- $\bullet$ sidered meaningful: more reliance can be attached to the pulmonary to systemic flow ratio. Pressures $\stackrel{\mathscr{\Phi}}{\mathscr{Q}}$ are measured with a greater degree of accuracy. Difficulty also attends the comparison of flows and $\vec{T}$ resistances at different ages for the range of normal is uncertain. Almost certainly the values ${ }_{0}^{\circ}$ change: for example, it appears likely that the pulmonary resistance in normal children falls as the $\stackrel{\mathbb{D}}{\circ}$ cardiac output increases with age (Brotmacher and Campbell, 1958). To try to minimize these difficulties we have related flows and resistance to surface area, expressing them as "indices." 
Equilibration of right and left ventricular pressures implies that the ventricles are functionally single, and this is said to be the case when the defect is larger than a critical size of $1 \mathrm{~cm} . .^{2} / \mathrm{m}^{2}$ of body surface area (Swan, Savard, and Kirklin, 1958). All our children had defects of critical size or greater when first investigated, but in searching for evidence as to whether a constant relation between area of defect and size of child continues throughout the years, allowance must be made for the different methods used for systemic and pulmonary blood flow measurement. In most cases the systolic pressures in the right ventricle and brachial artery remained within $20 \mathrm{~mm}$. $\mathrm{Hg}$ of each other, but a systemic systolic pressure exceeding the right ventricular systolic pressure by $57 \mathrm{~mm}$. $\mathrm{Hg}$ (Case 7) and $45 \mathrm{~mm} . \mathrm{Hg}$ (Case 8) suggests that the ventricles are no longer equilibrated and that the size of the defect has not kept pace with the growth of the child. In 3 other cases systemic pressure tended to increase more than the right ventricular pressure.

It is uncertain how the pulmonary circuit tolerates prolonged arterial hypertension. It might be anticipated that progressive secondary changes will occur with a tendency to a rising hindrance to flow, a view supported by Brotmacher and Campbell (1958) and Lillehei (1958). Our results suggest that this is by no means the rule. Although on average there was little change, the pulmonary resistance index dropped considerably in 2 children (Cases 3 and 7) and did not rise significantly in any. The pulmonary artery pressure fell or was unaltered in all but one. It appears that, at least before puberty, the passage of time is not necessarily associated with the development of irreversible changes in the small pulmonary arteries, a conclusion suggested by Lynfield et al. (1961). One of our patients was observed over the age period 15 to 20 years, and here also the pulmonary vascular resistance tended to fall. The pulmonary vascular resistance needs to be taken into account when assessing suitability for repair: by the criteria put forward by Goodwin (1961) two of our children were hardly acceptable when first investigated but were more suitable on the second occasion.

In the absence of necropsy data it is not possible to be sure that systolic gradients of from 26 to $68 \mathrm{~mm}$. Hg across the pulmonary valve mean organic stenosis and are not due merely to high rates of flow. Goodwin (1960) states that in patients with large ventricular septal defects such gradients are, in most cases, due to hypertrophic infundibular stenosis.

The two children with stenosis initially showed remarkable constancy of the dynamic pattern. It is not surprising that there should be no change in the pulmonary dynamics for the lungs are shielded from the high pressure right ventricle, but it is surprising that the degree of infundibular stenosis did not increase. It is possible that the stenosis is due to a morphologically abnormal outflow tract rather than to simple hypertrophy. Progressive stenosis may occur, however, and Becu et al. (1961) have reported conversion to the syndrome of the tetralogy of Fallot.

The two children developing pulmonary stenosis are of especial interest on account of the effects on pulmonary dynamics. In one of them the pulmonary resistance fell from 1172 to 492 units and the pulmonary to systemic flow ratio rose from $1 \cdot 7: 1$ to $3 \cdot 9: 1$. In the other the pulmonary resistance index fell from 501 to 303 units and the pulmonary to systemic flow ratio dropped from 3.8:1 to $1 \cdot 6: 1$. Different opinions are held concerning the reversibility of the pulmonary hypertension in ventricular septal defect with a raised pulmonary vascular resistance. Thus Evans and Short (1958) thought it to be due to permanent structural changes, Burchell (1959) stated that acetylcholine caused a slight decrease in pressure in only 1 of 3 cases, Swan and Wood and Marshall, (1957) found that breathing 100 per cent oxygen failed to produce a fall in pressure in some cases. Wood (1958) reported that acetylcholine did not produce a fall in pressure in the Eisenmenger syndrome. On the other hand Lillehei (1958) claimed that the pressures were reversible. There seems little doubt that in one of our children, shielding the pulmonary circuit from the high pressure input brought about a fall in pulmonary resistance although it was very high. In the other child the fall was less dramatic but the initial level was much lower.

Developing infundibular stenosis is analogous in many ways to "banding" the pulmonary artery, an operation claimed to be some help in seriously ill children with a large ventricular septal defect, pulmonary hypertension, and a left-to-right shunt. The aims of this operation are to reduce the pulmonary arterial pressure and to diminish left ventricular flow work by cutting down the shunt. 
In one child the reduction in pulmonary resistance more than offset the increased hindrance in the outflow tract, thus increasing the shunt and therefore left ventricular work. The possibility that "banding" if inadequate might have the same effect must be borne in mind.

There is little published material concerning changes in systemic flow in comparable cases. Our findings are that systemic flow does not keep pace with growth and this is, no doubt, causally related to the small stature of most of these children.

\section{Conclusions}

During the early years of life patients with a large ventricular septal defect, a left-to-right shunt, pulmonary hypertension, and a raised pulmonary vascular resistance do not deteriorate as might be expected. Progressive irreversible changes do not appear to take place in the pulmonary arteries and in some cases the size of the defect relative to the child diminishes. Early operation is thus not mandatory on these grounds, but the stunted growth resulting from inadequate systemic flow must be taken into account.

Some children will develop infundibular pulmonary stenosis which may bring about a drop in pulmonary resistance as well as pulmonary arterial pressure, but may also increase pulmonary flow and the pulmonary to systemic flow ratio.

If infundibular pulmonary stenosis exists from an early age the dynamics may remain constant.

\section{SUMMARY}

Ten children with large defects of the ventricular septum have been re-examined and re-catheterized after intervals of three to seven years. Two had infundibular pulmonary stenosis when first seen and two more developed it while under observation: none deteriorated. The findings are discussed in relation to the nature of pulmonary hypertension and the timing of surgical procedures.

We wish to thank Dr. A. Morgan Jones for his advice and for permission to investigate patients under his care and the Department of Medical Illustrations for the preparation of Fig. 1-7.

\section{REFERENCES}

Adams, P., Anderson, R. C., Allen, P., and Lillehei, C. W. (1959). Circulation, 16, 857.

Becu, L., Ikkos, D., Ljungquist, A., and Rudhe, U. (1961). Amer. J. Cardiol., 7, 598.

Brotmacher, L., and Campbell, M. (1958). Brit. Heart J., $20,97$.

Burchell, H. B. (1959). Brit. Heart J., 21, 255.

Downing, D. F. (1959). Amer. Heart J., 57, 669.

Evans, W., and Short, D. S. (1958). Brit. Heart J., 20, 529.

Fyler, D. C., Rudolph, A. M., Wittenborg, M. H., and Nadas, A. S. (1958). Circulation, 18, 833.

Goodwin, J. F. (1960). Clinical Disorders of the Pulmonary Circulation. Churchill, London. (1961). Proc. roy. Soc. Med., 54, 783.

Kay, E. B., Zimmerman, H. A., and Cross, F. S. (1955). J. thorac. Surg., 30, 452.

Lillehei, C. W. (1958). New Engl. J. Med., 258, 1044.

Lynfield, J., Gasul, B. M., Arcilla, R., and Luan, L. L. (1961). Amer. J. Med., 30, 357.

Marquis, R. M. (1950). Brit. Heart J., 12, 265.

Marshall, H. W., Swan, H. J. C., and Wood, E. H. (1957). Fed. Proc., 16, 84.

Morgan, B. C., Griffiths, S. P., and Blumenthal, S. (1960). Pediatrics, 25, 54.

Swan, H. J. C., Savard, R. M., and Kirklin, J. W. (1958). J. clin. Invest., 37, 934.

Wood, P. (1958). Proceedings of the International Conference on Pulmonary Circulation sponsored by the Chicago Heart Association, Chicago, Illinois. March 20 to 22. 